\title{
ECONOMIC FORMALISM FOR OPTIMIZING THE DESIGN AND ENERGY MANAGEMENT OF A HYBRID WIND/PHOTOVOLTAIC SYSTEM
}

\author{
O. GERGAUD, G. ROBIN, H. BEN AHMED, B. MULTON \\ SATIE - Brittany Branch, ENS de Cachan - Ker Lann Campus \\ 35170 BRUZ (France) - UMR 8029 CNRS
}

Phone: 33 (0)2-99-05-52-64 - Fax: 33 (0)2-99-05-93-28 - e-mail: gergaud@bretagne.ens-cachan.fr

\begin{abstract}
:
The objective herein is to establish a set of rules and tools for optimizing both energy management and design of a hybrid wind/photovoltaic production system, coupled to the grid and equipped with an electrochemical storage device. Optimization steps are carried out on the database containing consumption patterns and production resources. The chief optimization criterion is economic, with a focus on minimizing total cost of the system as well as of its installation and use over the long term (15 years). In this article, we will present the existing economic relationships inherent in such a system, prior to developing economic models for each of the various component units.
\end{abstract}

\section{Keywords:}

Economic formalism, hybrid wind/photovoltaic system, design optimization

\section{Introduction}

Our aim is to satisfy the energy-related demand of the consumer, given an assembly featuring the grid, wind and solar production systems, electrochemical accumulators and an inverter that coordinates energy flows between these elements (see Fig. 1).

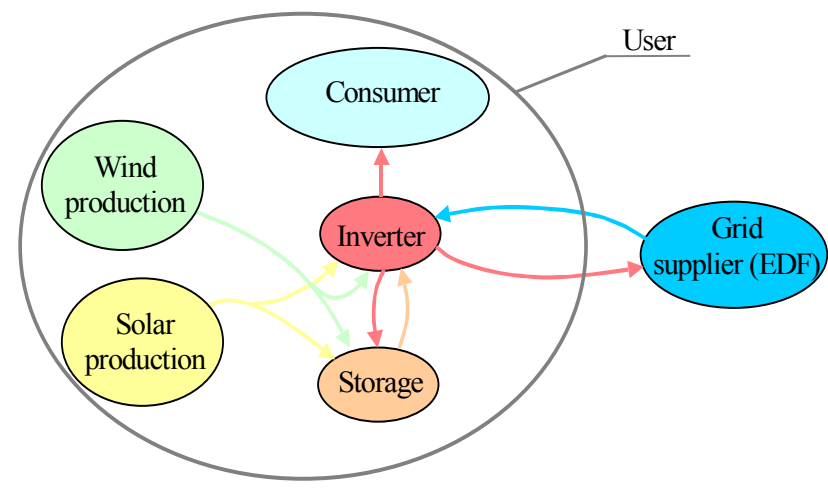

Fig. 1: Summary diagram of all possible energy exchanges
The notations used as well as the parameters characterizing each of these entities are described below:

- the consumer (an individual, local community, smallor medium-sized industry, etc.) at every point in time requires a certain quantity of energy for consumption purposes. In power terms, this consumption is denoted $P_{\text {conso }}(t)$;

- solar and wind energy producers generate at time $t$ a power of $P_{P V}(t)$ and $P_{W}(t)$, respectively. This level of power production depends on the following:

- solar and wind layers whose temporal distribution is given by the functions $G_{P V}(t)$ (insolation in $\mathrm{W} / \mathrm{m}^{2}$ ) and $G_{W}(t)$ (wind speed in $\mathrm{m} / \mathrm{s}$ ), respectively;

- ambient temperature $T_{a}(t)$ (in ${ }^{\circ} \mathrm{C}$ );

- peak power of installed production systems, $P_{p_{-} P V}$ for solar and $P_{p W}$ for wind (in peak watts);

- transfer functions (relations between electrical weather conditions and electricity production) of the cited wind and solar conversion chains $F_{W}$ and $F_{P V}$;

- continuous bus voltage imposed directly by the terminal voltage of the accumulator, $V_{b a t}(t)$;

- availabilities of the production systems $A_{P V}(t)$ and $A_{W}(t)$ in the event of maintenance or failure;

- voluntary unballasting of either production system $d_{W}(t)$ or $d_{P V}(t)$;

- the energy accumulator used herein is of the electrochemical type and characterized by its maximum storage capacity $E_{p_{-} b}$, its efficiency $\eta_{b}$, the peak power it is capable of providing or receiving $P_{p_{-} b}$, and its availability $A_{b}(t)$. We denote by $E_{b}(t)$ the energy stored in the battery and by $P_{b}(t)$ the power it receives or provides at time $t$;

- the reversible inverter is characterized by: the power forwarded to the inverter at time $t P_{c o n v}(t)$, maximum inverter power $P_{p_{-} c o n v}$, and inverter efficiency $\eta_{\text {conv }}$; 
- connection to the reversible grid is characterized by: the power provided or received at time $t \mathrm{P}_{\mathrm{G}}(\mathrm{t})$, maximum power capable of being provided or received $\mathrm{P}_{\mathrm{p}_{-} \mathrm{G}}$, and grid availability $\mathrm{A}_{\mathrm{G}}(\mathrm{t})$.

Figure 2 provides a general overview of the associated energy transfers and notations.

By definition, the following sign conventions will be adopted:

- $\quad P_{P V}(t) \geq 0$ and $P_{W}(t) \geq 0$;

- $P_{\text {conso }}(t) \geq 0$;
- $\quad P_{G}(t)<0$ when returning energy to the grid;

- $P_{G}(t)>0$ when the grid is providing energy to the system;

- $\quad P_{b}(t)<0$ when the accumulator is providing energy (mode discharges);

- $P_{b}(t)>0$ when the battery is receiving energy (mode charges);

- $E_{b}(t) \geq 0$.

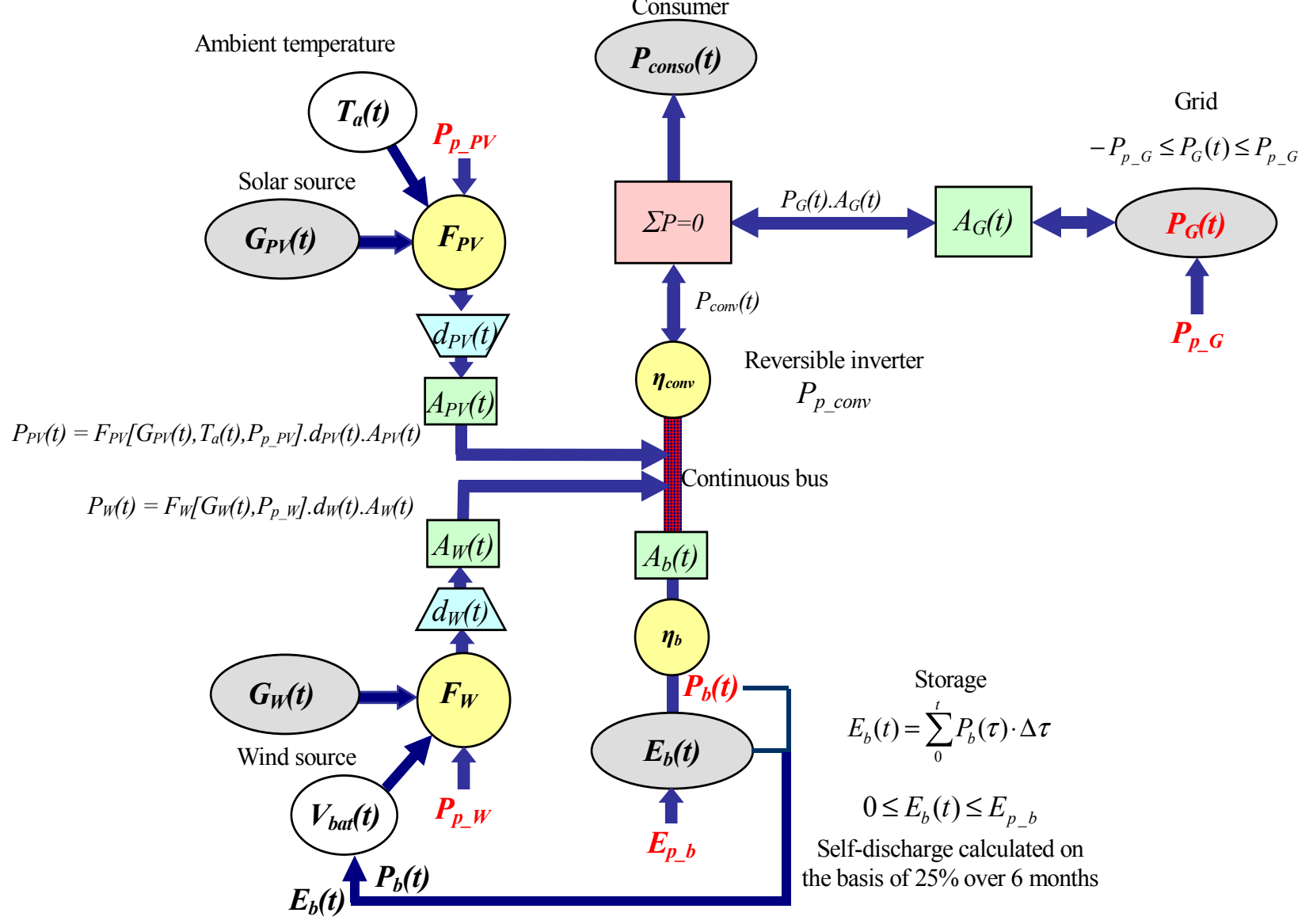

Fig. 2: General overview

System data consists of: power sources $G_{P V}(t)$ and $G_{W}(t)$, ambient temperature $T_{a}(t)$, and consumer consumption patterns $\mathrm{P}_{\text {conso. }}$ On the basis of this data set, our goal is to determine the values of the 9 parameters $\left(P_{p_{-} P V}, P_{p_{-} W}\right.$, $d_{P V}(t), d_{W}(t), E_{p_{-} b}, P_{p_{-} \text {ond }}, P_{p_{-} G}, P_{b}(t)$ and $\left.P_{G}(t)\right)$ that allow satisfying the consumer's energy needs. These parameters represent the decision-making variables, i.e.: peak power of production systems, production cutoff functions, storage capacity, peak power of the inverter and grid, and power flows through both the battery and grid. Among the range of solutions available for these 9 parameters, the optimal one is that offering the lowest use and installation costs.

\section{Economic relations}

The optimization of energy transfers and installed power will be conducted in accordance with economic criteria. A cost function must thereby be introduced for the user of each element within the complete system.

From a general perspective, we will define the cost of energy produced or consumed $C(t)$ by a given element at 
time $t$ (expressed in hours) as the sum of capital investment costs $C_{I}$ (purchase and installation), energy costs $C_{E}$ and use costs $C_{U}$ (operations and maintenance), respectively:

$$
C(t)=C_{I}(t)+C_{E}(t)+C_{U}(t)
$$

We will now proceed with the definitions of each of these component costs.

\section{A. Capital investment cost $C_{I}(t)$ :}

This cost depends on the maximum capacity of system elements $\left(P_{p_{-} P V}, P_{p_{-} W}, E_{p_{-} b}, P_{p_{-} \text {conv }}\right.$ or $\left.P_{p_{-} G}\right)$. It may be expressed in the following form:

$$
C_{I}(t)=C_{I 0}+\frac{C_{I 1}}{8766} \cdot t \cdot A m(t)
$$

with:

- $C_{I 0}$ : portion of the payment remitted upon installation;

- $C_{I I}$ : portion of the payment spread in time (annual cost) over a number of years $N_{a}$ at an annual interest rate $\delta$. Generally, given a total purchase and installation cost CT of an installation of capacity Cmax, we obtain:

$$
\begin{aligned}
& C_{I 1}=\frac{\left[C_{T}\left(C_{\max }\right)-C_{I 0}\right] \cdot \delta \cdot(1+\delta)^{N_{a}}}{(1+\delta)^{N_{a}}-1} \\
& A m(t)=\left\{\begin{array}{lll}
1 & \text { if } & t \leq 8766 \cdot N_{a} \\
0 & \text { if } & t>8766 \cdot N_{a}
\end{array}\right.
\end{aligned}
$$

We have counted 8,766 hours for one year.

\section{B. Energy $\operatorname{cost} C_{E}(t)$}

This cost depends on both the power produced or consumed $x(t)$ at time $t$ and the maximum power $x_{\max }$ capable of being received or transmitted by the element. This cost expression assumes the following form:

$$
C_{E}(t)=\sum_{0}^{t} \alpha\left[x_{\max }, \operatorname{sign}(x(\tau)), t\right] \cdot x(\tau) \cdot \Delta \tau
$$

with $\alpha$ being the unit purchase or selling price of energy, expressed in $€ / \mathrm{kWh}$.

\section{Use $\operatorname{cost} C_{U}(t)$ :}

This cost may be broken down into an annual maintenance cost, which depends on the capacity $\mathrm{C}_{\max }$ of the installation, and a facilities renewal cost, tied to all production-induced wear:

$$
C_{U}(t)=\frac{\beta\left(C_{\max }\right)}{8766} \cdot t+\sum_{0}^{t} \gamma \cdot|x(\tau)| \cdot \Delta \tau
$$

with:

- $\beta$ being the fixed average annual cost related to regular maintenance, facilities rental charges or a service account;

- $\gamma$ being the fixed average cost related to system wear (unit energy cost).

By determining all these parameters for the various elements composing the system, we thereby obtain the user cost function. The expression of this cost for an individual element however may differ depending on the selected configuration.

Indeed, whether the user is just the consumer (see Fig. $3 a)$ or both the consumer and producer at the same time (Fig. 3b), the user cost related to this production system will not be the same.

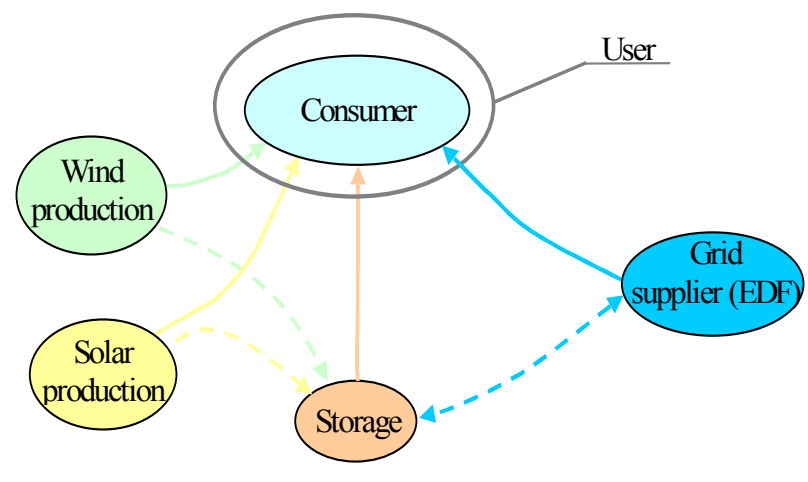

a)

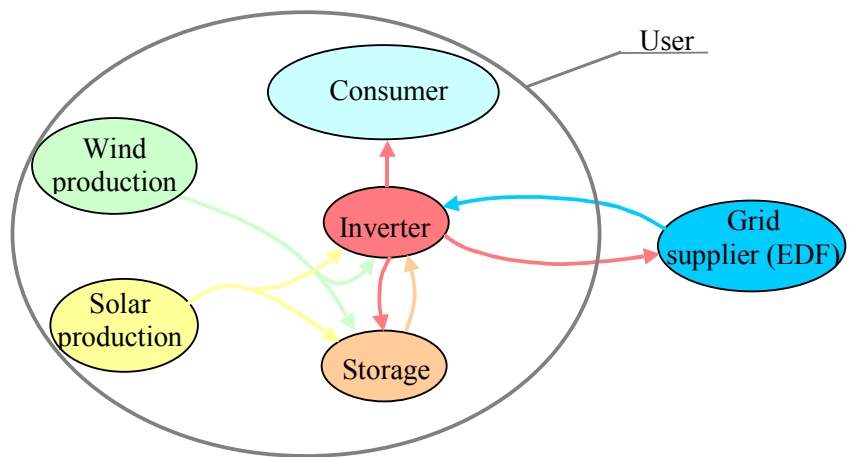

b)

Fig. 3: a) Overview of energy exchanges when the user is just the consumer; b) Overview of energy exchanges when the user is both consumer and producer at the same time

For configuration b) above, once the production system has been acquired, whether or not this system actually produces, user cost will not be affected (outside of the impact on maintenance costs). On the other hand, if the user is only the consumer (configuration a), then the cost related to a system of unspecified production is determined merely as the sum of costs required to access the grid plus an energy cost directly related to the energy provided by this producer. In this case, the production and storage systems are perceived by the user in the same way as by the principal supplier. This situation was not altogether feasible a few years ago; however, since the liberalization of the electricity market, which has tended to spread throughout the wealthier countries, it has now become entirely realistic. The choice between the various 
suppliers will be made by an analysis of subscription prices, energy costs and the quality of services proposed. Yet this choice could also be made, albeit with greater difficulty, on the basis of simple economic criteria. If producing at the lowest cost were sufficient for successfully developing a market, the environmental and quality consequences would most likely be quite serious. For the study performed herein, we have positioned ourselves from the standpoint as if the user were both a producer and consumer connected to a principal network of infinite power (see Fig. 3b).

We then obtain the following cost function:

- For solar production (net of production-related wear, zero energy cost):

$C_{P V}(t)=C_{I_{-} P V}\left(P_{p_{-} P V}, t, N_{a}, \delta\right)+\frac{\beta_{P V} \cdot P_{p_{-} P V}}{8766} \cdot t$

- For wind production (zero energy cost):

$$
\begin{aligned}
C_{W}(t)= & C_{I_{-} W}\left(P_{p_{-} W}, t, N_{a}, \delta\right)+\frac{\beta_{W} \cdot P_{p_{-} W}}{8766} \cdot t \\
& +\sum_{0}^{t} \gamma_{W}\left(P_{p_{-} W}\right) \cdot P_{W}(\tau) \cdot \Delta \tau
\end{aligned}
$$

- For storage (zero energy cost):

$$
\begin{aligned}
C_{b}(t)= & C_{I_{-} b}\left(P_{p_{-} b}, t, N_{a}, \delta\right)+\frac{\beta_{b} \cdot P_{p_{-} b}}{8766} \cdot t \\
& +\sum_{0}^{t} \gamma_{b} \cdot\left|P_{b}(\tau)\right| \cdot \Delta \tau
\end{aligned}
$$

- For the network (net of wear, net of maintenance costs):

$$
\begin{aligned}
C_{G}(t) & =C_{I_{-} G}\left(P_{p_{-} G}, t, N_{a}, \delta\right)+\frac{\beta_{G}\left(P_{p_{-} G}\right)}{8766} \cdot t \\
& +\sum_{0}^{t} \alpha_{G}\left[P_{p_{-} G}, \operatorname{signe}\left(P_{G}(\tau)\right), \tau\right] \cdot A_{G}(\tau) \cdot P_{G}(\tau) \cdot \Delta \tau
\end{aligned}
$$

- For the inverter (only one purchase and installation cost related to its maximum power $\left.\mathrm{P}_{\mathrm{p} \_ \text {conv }}\right)$ :

$$
C_{\text {conv }}(t)=C_{I_{-} \text {conv }}\left(P_{p_{-} \text {conv }}, t, N_{a}, \delta\right)
$$

Knowing the relation $\sum P=0$, we can easily deduce the total user-related cost at time $\mathrm{t}$, given the following:

$$
\begin{aligned}
& C_{\text {Tot }}(t)=C_{I_{-} W}\left(P_{p_{-} W}, t, N_{a}, \delta\right)+C_{I_{-} P V}\left(P_{p_{-} P V}, t, N_{a}, \delta\right) \\
& +C_{I_{-} b}\left(P_{p_{-} b}, t, N_{a}, \delta\right)+C_{I_{-} G}\left(P_{p_{-} G}, t, N_{a}, \delta\right) \\
& +C_{I_{-} c o n v}\left(P_{p_{-} c o n v}, t, N_{a}, \delta\right) \\
& +\frac{\beta_{W} \cdot P_{p_{-} W}+\beta_{P_{V}} \cdot P_{p_{-} P V}+\beta_{b} \cdot P_{p_{-} b}+\beta_{G}\left(P_{p_{-} G}\right)}{8766} \cdot t \\
& +\sum_{0}^{t} \alpha_{G}\left[P_{p_{-} G}, \operatorname{signe}\left(P_{G}(\tau)\right), \tau\right] \cdot A_{G}(\tau) \cdot P_{G}(\tau) \cdot \Delta \tau \\
& +\sum_{0}^{t} \gamma_{W}\left(P_{p_{-} W}\right) \cdot P_{W}(\tau) \cdot \Delta \tau+\sum_{0}^{t} \gamma_{b} \cdot\left|P_{b}(\tau)\right| \cdot \Delta \tau
\end{aligned}
$$

The economic problem of optimizing energy transfers over a given period $T$ is mathematically expressed by minimizing the cost function in Equation (12) subject to the following constraints:

$$
\left\{\begin{array}{l}
P_{\text {conso }}(t)=F_{W}\left[G_{W}(t), P_{p-W}\right] \cdot A_{W}(t) \cdot d_{W}(t) \\
\quad+F_{P V}\left[G_{P V}(t), T_{a}(t), P_{p-P V}\right] \cdot A_{P V}(t) \cdot d_{P V}(t) \\
\quad-P_{b}(t) \cdot A_{b}(t)+A_{G}(t) \cdot P_{G}(t) \\
E_{b}(t) \leq E_{p_{-} b} \\
\left|P_{G}(t)\right| \leq P_{p_{-} G} \\
\left|P_{b}(t)\right| \leq P_{p_{-} b} \\
\left|P_{\text {conv }}(t)\right| \leq P_{p_{-} \text {conv }}
\end{array}\right.
$$

In order to analyze this problem, we will base our approach on simple cases. To obtain a quantitative analysis of the system however, we must know the data required to solve the given problem.

\section{Parameter determination}

\section{A. Parameters related to the principal network:}

\section{1) Cost of grid connection:}

The connection rates used have been taken from the Bouches-du-Rhône (southeastern France) Electrical Authority's rate table [1], which is broken down into two parts: the first extends to the property boundary of the given installation; and the second includes connection onto private property. For an $18-\mathrm{kVA}$ capacity connection extending to the property boundary, the amount in euros according to $L_{r a c}$, the distance in meters between the property boundary and the nearest lowvoltage network, is evaluated by the following expressions:

$$
C_{\text {rac_ext }}\left(L_{\text {rac }}\right)=\left\{\begin{array}{clr}
700 & \text { if } & L_{\text {rac }} \leq 30 \\
700+14 \cdot\left(L_{\text {rac }}-30\right) & \text { if } & 30<L_{\text {rac }} \leq 200 \\
700+14 \cdot(200-30)+27 \cdot\left(L_{r a c}-200\right) & \text { if } & L_{\text {rac }}>200
\end{array}\right.
$$

The portion of the connection rate through private property is invoiced as a supplement, at a rate of $25 € / \mathrm{m}$, 
with $l_{\text {rac }}$ denoting the length of internal connection in meters:

$$
C_{\text {rac_int }}\left(l_{\text {rac }}\right)=25 \cdot l_{\text {rac }}
$$

If the power needed by the customer, either at the time of connection or subsequently, lies between 18 and $36 \mathrm{kVa}$, a complement of $250 €$ is then invoiced for work performed that results in raising the connection capacity to $36 \mathrm{kVa}$.

The total cost of connection to the French electrical utility (EDF) network thus amounts to:

$$
C_{T \_r a c}\left(L_{r a c}, l_{r a c}\right)=\left\{\begin{array}{cl}
C_{r a c \_e x t}\left(L_{r a c}\right)+C_{r a c \_ \text {int }}\left(l_{\text {rac }}\right) & \text { if }<18 k V A \\
C_{r a c \_e x t}\left(L_{r a c}\right)+C_{r a c \_ \text {int }}\left(l_{r a c}\right)+250 & \text { if } \geq 18 k V A
\end{array}\right.
$$

By means of example therefore, for a user whose installation is located 20 meters from the property boundary with a capacity of $9 \mathrm{kVa}$, we are able to plot the cost of connection as a function of the distance $L_{\text {rac }}$ from the low-voltage grid, as represented on the following figure:

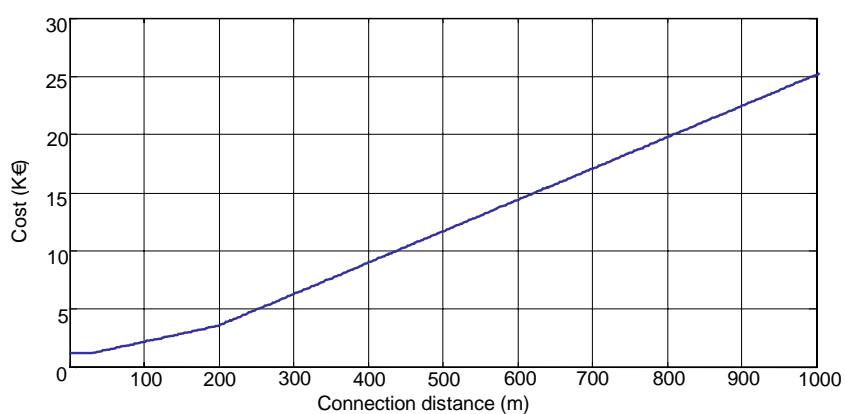

Fig. 4: Cost of connection to the grid vs. distance between the property and the low-voltage grid for an apparent power of $9 \mathrm{kVA}$

2) Subscription price and energy cost of the principal network in Metropolitan France:

Both the subscription price $\left(\beta_{G}\right)$ and energy cost $\left(\alpha_{G}\right)$ result from the rates applied by the grid supplier, EDF [2], for Metropolitan France.

With regard to the repurchase rate of electrical power by the principal supplier, we will apply the general rate scale of a power installation of less than $36 \mathrm{kcVa}$, i.e. 4.42 euros/kWh [3].

Three rate options are suggested by EDF; for each of these options, the subscription price depends on the installed working capacity, while the energy cost is either fixed or time-variable according to the selected option. Only the basic option will be considered herein:

Table 1: Subscription price and energy cost of the principal grid in Metropolitan France - "Basic" Option

\begin{tabular}{|c|c|c|}
\hline $\begin{array}{c}\text { Power } \\
\text { rating } \\
\text { (kVA) }\end{array}$ & $\begin{array}{c}\text { Annual } \\
\text { subscription price } \\
\text { (including tax, in euros) }\end{array}$ & $\begin{array}{c}\text { Cost per kWh } \\
\text { (including tax, in euros) }\end{array}$ \\
\hline 3 & 23.16 & \multirow{2}{*}{0.1258} \\
\hline 6 & 58.96 & \multirow{2}{*}{0} \\
\hline 9 & 116.23 & \multirow{2}{*}{0.1032} \\
\hline 12 & 166.77 & \\
\hline 15 & 217.31 & \\
\hline 18 & 267.84 & \\
\hline 24 & 447.24 & \\
\hline 30 & 626.65 & \\
\hline 36 & 806.05 & \\
\hline
\end{tabular}

With this option, the following characteristics are then obtained for parameters $\beta_{G}$ and $\alpha_{G}$ :
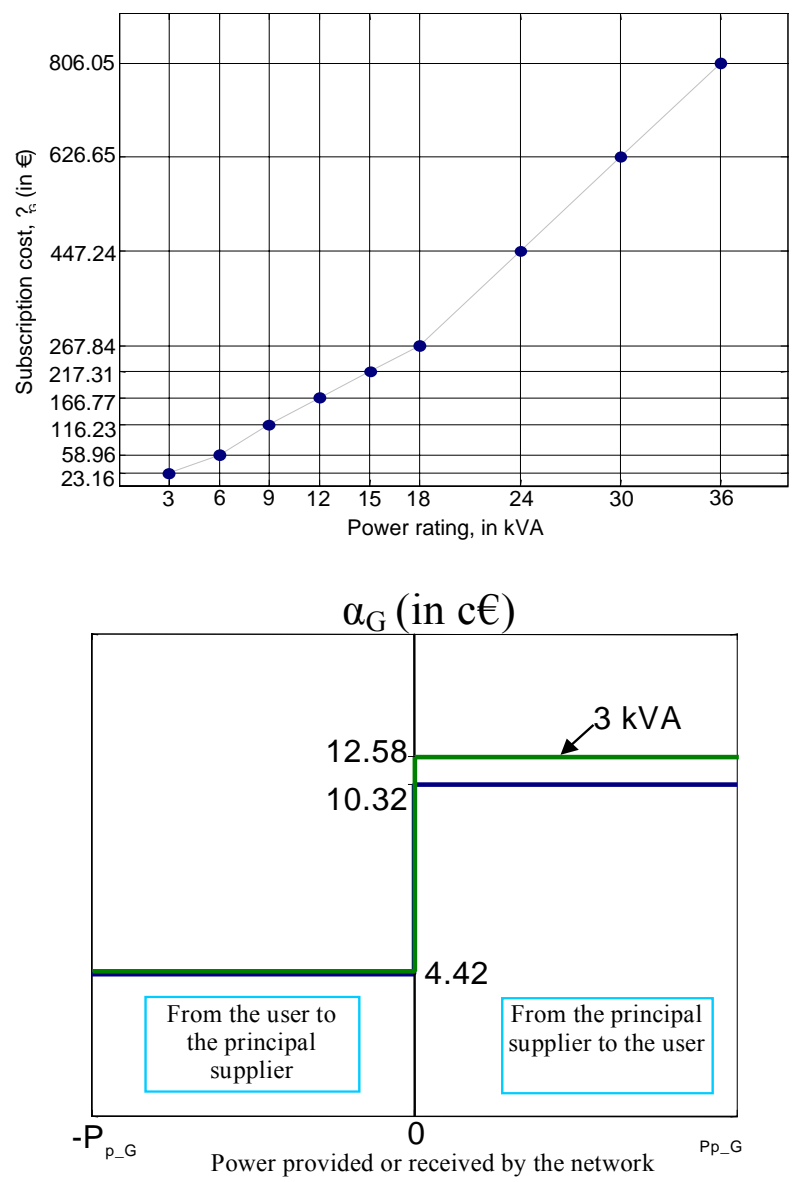

Fig. 5: Characteristics of parameters $\beta_{G}$ and $\alpha_{G}$ - top: $\beta_{G}$ vs. $P_{p_{-} G} ;$ bottom: $\alpha_{G}$ vs. $P_{G}(\tau)$

B. Economic parameters related to the photovoltaic generator:

The price of a photovoltaic installation must take into account the actual elements, which are broken down between the set of conversion materials, labor and installation startup. The material component includes: photovoltaic panels, converters and all necessary connection cables. Total cost of the photovoltaic installation varies from one source to the next, to an increasing extent since strong market expansion is being 
accompanied by sharp reductions in the price of panels and the installation component may be subject to great dispersion depending on the associated difficulties. The converters, still manufactured in small series, should in the future undergo significant cost decreases with an installation cost per peak watt expected to drop as power increases [4].

For our purposes, we will assume a constant cost of $6 €$ per installed peak watt [5]. For the trends in both cost per peak watt and total photovoltaic installation cost vs. peak installed power $\left(P_{p_{-} P V}\right)$, this set-up yields the following equations:

$$
\begin{aligned}
& C_{P V}=6(€ / \mathrm{Wc}) \\
& C_{T_{-} P V}=6 \cdot P_{p_{-} P V}(€)
\end{aligned}
$$

which then leads to the characteristic displayed in the following figure:

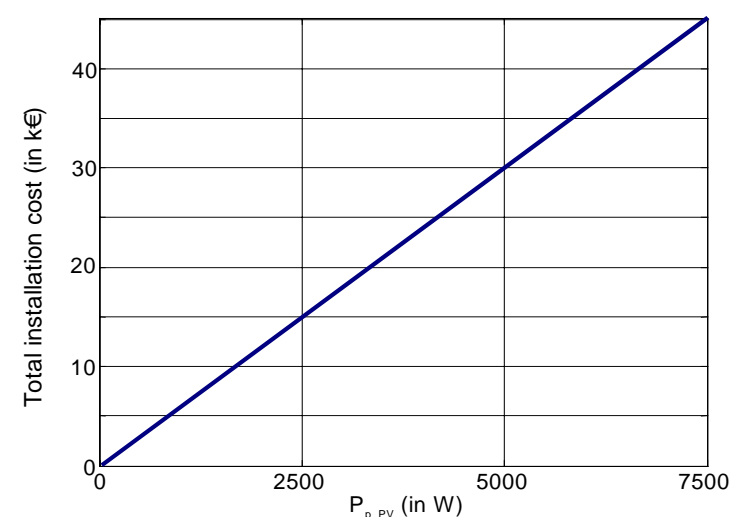

Fig. 6: total installation cost vs. $P_{p_{P} P V}$, the peak installed power

Once this system has been installed, an operations and maintenance cost is to be applied. This cost is evaluated by [5] at $0.1 \mathrm{c} € / \mathrm{kWh}$ produced per installed peak watt.

If we estimate that every installed metered peak watt produces $1 \mathrm{kWh}$ a year, we then obtain the following estimate of annual maintenance costs:

$$
\beta_{P V}=0.1 \mathrm{c} € / \mathrm{Wc} / \text { year }
$$

\section{Economic parameters related to the wind generator:}

It is very difficult to calculate the price of a wind installation without considering the actual situation. The cost is broken down between materials, labor, civil engineering and installation assembly startup. This decomposition may be quite variable from one installation site to the next (topographical difficulties, distance between aerogenerators and ground installation, etc.).

The materials involved herein include: windmills, chechmates, converters and all necessary connection cables. Let's take, for example, an installation of small windmills $(<5 \mathrm{kWc})$, with a $10 €$ cost per installed Wc [6] (very expansive comported to large machines with investment cost less than $1 € / \mathrm{W}_{\mathrm{c}}$. We then consider, for installation cost $\left(C_{W}\right)$ and total wind system cost $\left(C_{T_{-} W}\right)$ with respect to peak installed power $\left(P_{p_{-} W}\right)$, the following equations:

$$
\begin{aligned}
& C_{W}=10(€ / \mathrm{Wc}) \\
& C_{T_{-} W}=10 \cdot P_{p_{-} W}(€)
\end{aligned}
$$

This set-up leads to the characteristic displayed in the following figure:

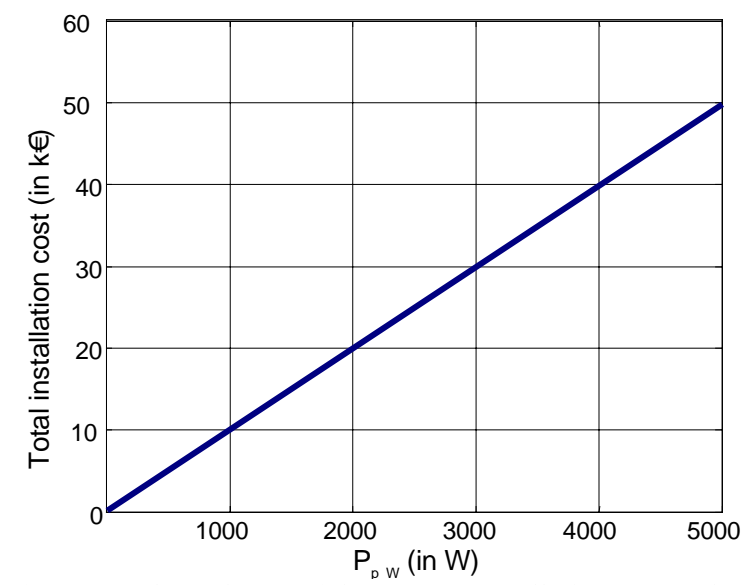

Fig. 7: Total wind cost of the system installed vs. $P_{p_{-} W}$, the peak power

Operations and maintenance costs are evaluated by [5] at $1 \mathrm{c} € / \mathrm{kWh}$ produced. Only the cost of implementation is then dependent upon production, i.e.:

$$
\begin{aligned}
& \gamma_{W}=1 \mathrm{c} € / \mathrm{kWh} \\
& \beta_{W}=0 € / \mathrm{Wc} / \text { year }
\end{aligned}
$$

\section{Economic parameters of storage:}

The cost of an electrochemical storage system (lead-acid seals) is considered to be $210 € / \mathrm{kWh}$ [7] installed, including approximately $5 \%$ for the installation. This cost encompasses the electrochemical accumulators, all necessary connection cables, the cabinet or containment trunk, as well as unit startup costs:

$$
C_{T_{-} b}=210 \cdot E_{p_{-} b}(€)
$$

Maintenance-related costs are composed of a portion determined by annual maintenance functions, independent of battery operations $\left(\beta_{b}\right)$ ) and a second portion related to battery cycling-induced wear $\left(\gamma_{b}\right)$. In general, the batteries installed in such applications are considered to be "maintenance-free". Lacking information on annual maintenance costs, let's consider them herein to be zero:

$$
\beta_{b}=0
$$

As for the battery wear-related cost, let's recall the following form:

$$
C_{b_{-} \text {wear }}(t)=\sum_{0}^{t} \gamma_{b} \cdot\left|P_{b}(\tau)\right| \cdot \Delta \tau
$$


This cost actually depends on the number and amplitude of the cycles the battery is undergoing. In adopting the assumption that this number remains constant regardless of the cycle amplitude of the battery used, the ratio of the total price of batteries to the number of cycles yields the per-cycle cost. It is then sufficient to simply count the number of cycles that the battery underwent at time $t$ in order to derive the wear-related cost at this same moment. Counting the number of cycles however is a complicated task in an operating mode with high battery demand and, in reality, where the number of cycles depends heavily on the way in which electrochemical accumulator demand is being handled. By observing data over the entire lifespan as a function of discharge depth (see Fig. 8 [8]), we have remarked that the assumption of a constant product when multiplying number of cycles by discharge depth can be reasonably made:

\section{(Number of cycles $) \times($ Discharge depth $)=N_{p}=C s t$}

The product of parameter $N_{p}$ and twice (charge + discharge) the maximum battery capacity $E_{p_{b} b}$ then yields the total energy capable of being forwarded within the battery during load and discharge, i.e. on the whole:

$$
2 \cdot N_{p} \cdot E_{p_{-} b}=\sum_{0}^{t}\left|P_{b}(\tau)\right| \cdot \Delta \tau
$$

The ratio of total battery price to $2 \cdot N_{p} \cdot E_{p_{-} b}$ then gives the exchange cost of an energy unit. In the following discussion, we will set $N p=1350$ (in accordance with the reference figures [8]):

$$
\gamma_{W}=\frac{\text { Total_battery_cos } t}{2 \cdot N_{p} \cdot E_{p_{-} b}}=\frac{210}{2 \cdot N_{p}}=0.077(\text { in } € / \mathrm{kWh})
$$

Let's note that the concept of lifespan is complex because the accumulator, as it ages, gradually loses its storage capacity and moreover its electrical characteristics change. This problem however lies beyond the scope of the present article and will not be addressed herein. Figure 8 shows the evolution in number of cycles vs. discharge depth [8] as well as the evolution obtained using the preceding assumption:

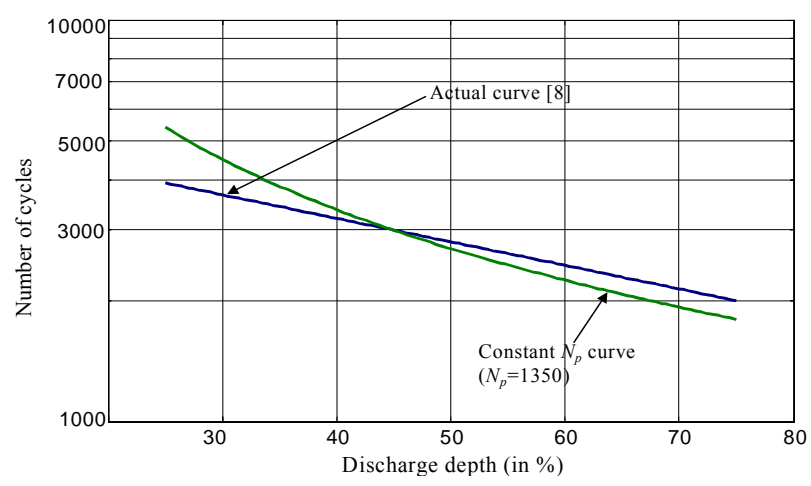

Fig. 8: Evolution in the number of cycles vs. discharge depth, model and actual data [8]
This figure indicates that our assumption provides a good estimate of the number of cycles for discharge depths greater than $40 \%$. Below this value, the potential number of cycles is overestimated. However, the curve of actual data, provided by [8], simply proposes an evolution trend in the number of cycles vs. discharge depth and cannot be rigorously identical for all batteries. This representation largely simplifies our approach in that any level of rigor would call for counting (and thus detecting) each cycle whereas, thanks to this assumption, we merely need to quantify the energy being forwarded in order to identify the state of wear. A cycle count (in terms of both amplitude and number) can prove very complicated in an application like ours (see Fig. 9).

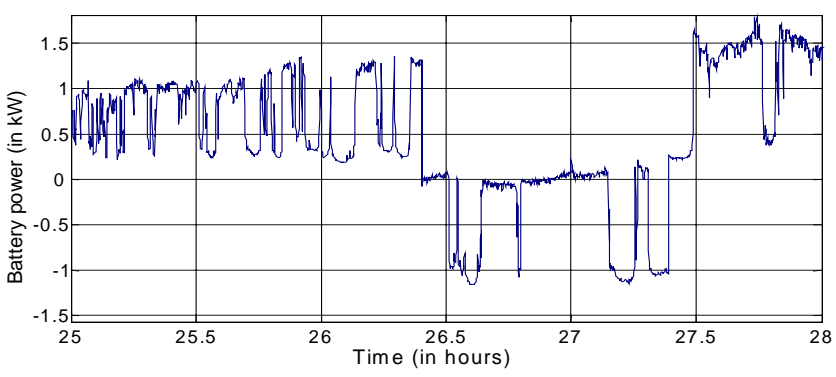

Fig. 9: Example of battery operations highlighting the complexity of cycles, in an application that includes production by means of renewable sources operating autonomously

E. Economic parameters related to the inverter:

Only the inverter purchase and installation costs are considered herein. For purposes of illustration, [9] provides the evolution, as a function of power, for the price of inverters generating less than $5.5 \mathrm{kVA}$ of power. We will thus employ the following cost function, in assuming that installation accounts for $10 \%$ of the price of the inverter:

$$
C_{T_{-} \text {ond }}=\left\{\begin{array}{ccc}
1178 & \text { if } & p_{\text {conv }} \leq 1 \mathrm{kVA} \\
1074 \cdot p_{\text {conv }}+104 & \text { if } & 1 \mathrm{kVA}<p_{\text {conv }} \leq 4 \mathrm{kVA} \\
500 \cdot\left(P_{\text {conv }}-4\right)+4400 & \text { if } & P_{\text {conv }}>4 \mathrm{kVA}
\end{array}\right.
$$

which yields the cost evolution shown in Figure 10 below:

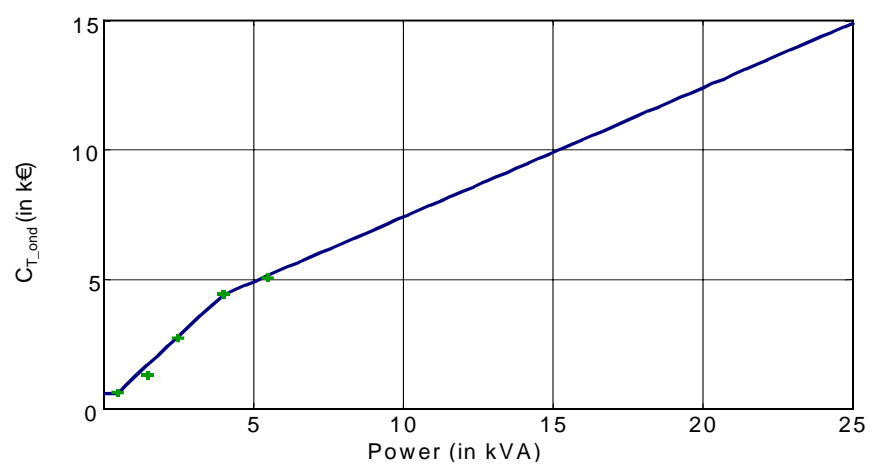

Fig. 10: Total cost of the installed inverter vs. inverter power 


\section{Conclusion}

In this article, we have established general economic relations within a multiple (wind and solar) electricity production system, coupled to the grid and connected with a storage device. The economic models of the various component elements have also been presented.

The economic relations used, in conjunction with energy models of the complete system [10] [11], have enabled us to derive a comprehensive technical/economic model of the system, which proves essential to both design and energy management optimization [12] (figure 11). This optimizations for a user given on a given site are carried out with profile of consumption and characteristics of the site, in particular the data which will make it possible to consider the production possible.

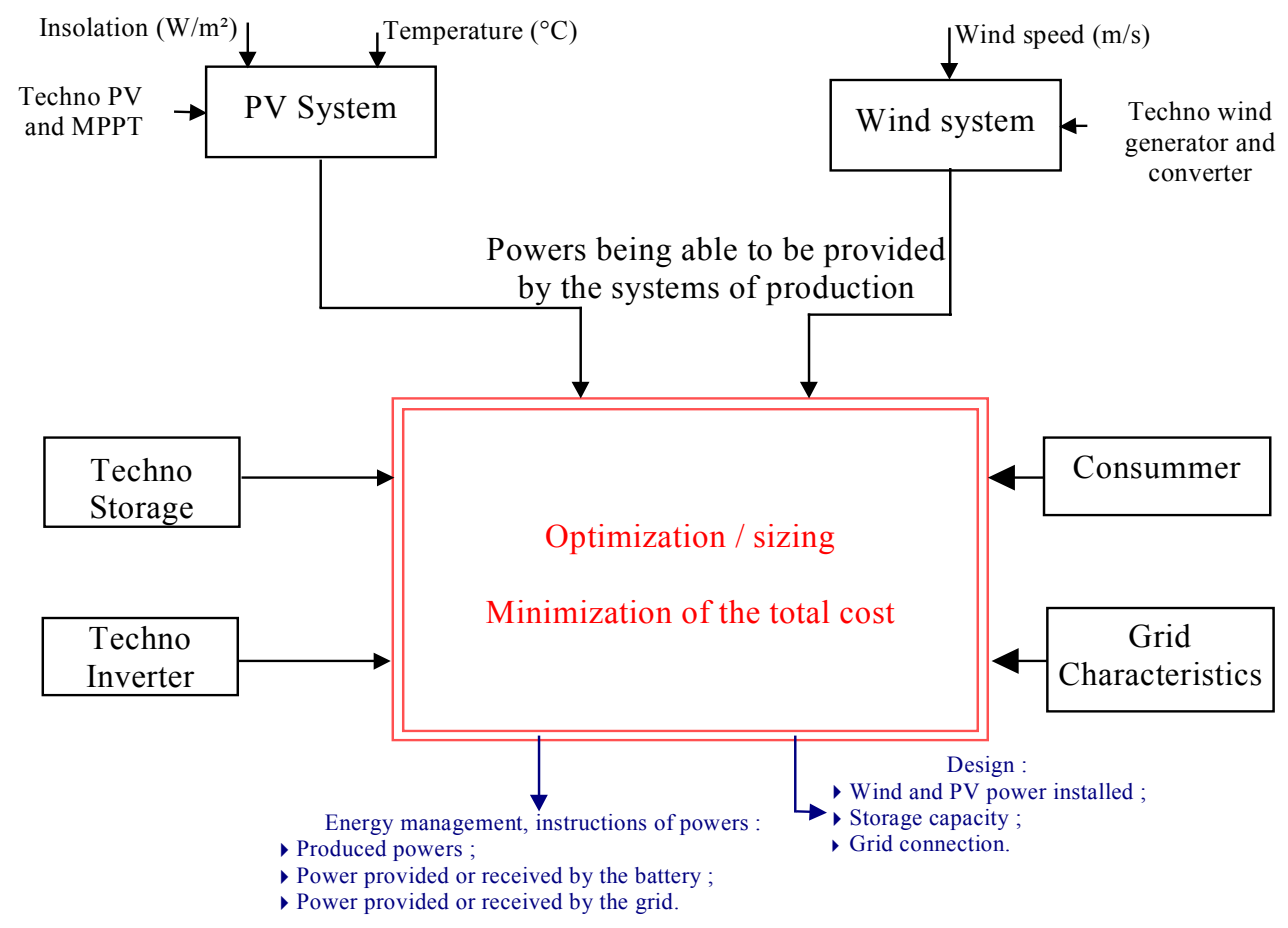

fig. 11 : Synoptic of both design and energy management optimization on the basis of data of consumption and weather

\section{References}

[1] Internet site of the « Syndicat Mixte d'Electrification des Bouches du Rhône », (southeastern France) http://www.smed13.com/Concession electrique/ce4.htm

[2] Internet site of the "Electricité de France ", www.edf.fr

[3] "Arrété du 13 mars 2002 fixant les conditions d'achat de l'électricité produite par les installations d'une puissance inférieure ou égale à $36 \mathrm{kVA}$ pouvant bénéficier de l'obligation d'achat ». NOR : ECOI0100648A, Journal Officiel (France) numéro 62 du 14 mars 2002 page 4620.

[4] P. BOULANGER, P. MALBRANCHE, « Conversion de puissance et gestion d'énergie dans les systèmes photovoltaïques: état de l'art», colloque GEVIQ'2002, Marseille 12-13 juin 2002, pp.60-65.

[5] Internet site of the institute of the energy and the environment of the French-speaking « la génération répartie d'électricité : Enjeux, Techniques et perspectives » http://www.agora21.org/energie/iepf/mayer.html

[6] Internet site of the information center on energy and the environment, CIELE, http://www.ciele.org
[7] Internetsit of the " énergies nouvelles entreprise », http://perso.wanadoo.fr/energies-nouvellesentreprises/10.htm

[8] R. MESSENGER, J. VENTRE, Photovoltaic Systems Engineering, CRC Press, 1999.

[9] Internet site of the American manufacturerTRACE http://www.traceengineering.com/

[10] O. GERGAUD, B. MULTON, H. BEN AHMED, "Modélisation d'une chaîne de conversion éolienne de petite puissance", Electrotechnique du Futur 2001 nov. 2001, Nancy France, pp.17-22.

[11] O. GERGAUD, B. MULTON, H. BEN AHMED, "Analysis and Experimental Validation of various Photovoltaic System Models", $7^{\text {th }}$ International ELECTRIMACS 2002 Congress, Aug. 2002, MONTREAL Canada.

[12] O. GERGAUD “ Energy modeling and economic optimization of a hybrid wind/photovoltaic system coupled with the grid and associated an accumulator ", thesis supported in SATIE (Brittany Branch) on December 9, 2002.

Download :

http://www.bretagne.ens-cachan.fr/dochtml/docD/ pdf/these complete\%20O.GERGAUD.pdf 